\title{
Analysis of Ultrasonography and Diagnostic Laparoscopy in Nonpalpable Testis
}

\author{
Raj Kumar Sahu ${ }^{1}$, Rajendra Prasad Gorthi², Venkataramana Poondla ${ }^{3}$, Vaibhav Chapara ${ }^{4}$ \\ ${ }^{1}$ Department of Paediatric Surgery, Andhra Medical College, Visakhapatnam, Andhra Pradesh, India. \\ ${ }^{2}$ Department of Paediatric Surgery, Andhra Medical College, Visakhapatnam, Andhra Pradesh, India. \\ ${ }^{3}$ Department of Paediatric Surgery, Andhra Medical College, Visakhapatnam, Andhra Pradesh, India. \\ ${ }^{4}$ Department of Paediatric Surgery, Andhra Medical College, Visakhapatnam, Andhra Pradesh, India.
}

\section{ABSTRACT}

\section{BACKGROUND}

Undescended testis is one of the common disorders encountered in a male child. In nonpalpable testis, ultrasound often fails to locate the testis. Hence, diagnostic laparoscopy has recently replaced it in the management of nonpalpable testis.

\section{METHODS}

This is a cross-sectional study conducted among all patients who presented between October 2018 and March 2020 with a nonpalpable testis and in whom ultrasound could not locate the testis. Analysis of ultrasound and diagnostic laparoscopy in nonpalpable testis was done. Statistical analysis was done by calculating accuracy, sensitivity, and specificity for selected tests.

\section{RESULTS}

20 patients were included in the study. Most of them (95\%) presented after 1 year. Most cases were unilateral $80 \%$; left-sided in $45 \%$, right sided in 35\%, and 4 (20\%) were bilateral. In $25 \%$ cases, the testis was located at the deep inguinal ring, and in $70 \%$ cases, it was intra-abdominal, although in 2 cases the testes were tiny like a nubbin. In 1 case, the vessels and vas entered the deep inguinal ring; hence inguinal exploration was done; however, as only a nubbin was found on exploration, orchidectomy was done. In 1 patient inguinal exploration done, whereas other patients were managed laparoscopically. In 2 patients, laparoscopic orchidectomy and in others, laparoscopic-assisted orchiopexy were done.

\section{CONCLUSIONS}

Laparoscopy is superior to ultrasound because of increased sensitivity in localizing a nonpalpable testis, time- and cost-effectiveness, and diagnostic as well as therapeutic options.

\section{KEY WORDS}

Ultrasound, Diagnostic Laparoscopy, Nonpalpable Testis
Corresponding Author:

Dr. Raj Kumar Sahu,

Valley Front Apartment, Flat No. 501,

D. No. 5-178/59, Gollala Yendada,

Near Sun Beach Campus, Visakhapatnam

Rural, Visakhapatnam-530045,

Andra Pradesh, India.

E-mail: raj.bapisahu@gmail.com

DOI: $10.14260 / \mathrm{jemds} / 2020 / 460$

How to Cite This Article:

Sahu RK, Gorthi RP, Poondla V, et al. Analysis of ultrasonography and diagnostic laparoscopy in nonpalpable testis. J. Evolution Med. Dent. Sci. 2020;9(30):21092113, DOI: $10.14260 /$ jemds/2020/460

Submission 08-04-2020,

Peer Review 18-06-2020,

Acceptance 24-06-2020,

Published 27-07-2020.

Copyright (C) 2020 JEMDS. This is an open access article distributed under Creative Commons Attribution License [Attribution 4.0 International (CC BY 4.0)] 


\section{BACKGROUND}

Cryptorchidism or undescended testis i.e. absence of testis in the scrotum, is a common disorder encountered in a male child. The incidence may vary from $1.0-4.6 \%$ at birth in fullterm neonates. ${ }^{1}$

Testicular descent occurs in two phases: transabdominal descent which occurs at approximately 22-25 weeks gestational age, and inguinoscrotal migration which occurs at 25-30 weeks gestational age. ${ }^{2}$ As the testicular migration through the inguinal canal occurs relatively late in gestational development, cryptorchidism is seen accordingly higher in premature boys in the first few months of life. However, there is still a possibility that there may be spontaneous descent during the initial months of life, and hence the incidence drops down to $1 \%$ at 1 year of age. ${ }^{3}$

Undescended testis is classified mainly depending on the clinical examination. It is classified into a palpable and nonpalpable testis. Approximately $80 \%$ of the undescended testes are palpable and rest $20 \%$ are nonpalpable. ${ }^{4}$ The palpable testis can be further categorised as prescrotal, inguinal, and canalicular depending on the location of the testis.

There are various reasons for which a testis is not palpable. A testis may be impalpable because of intra-uterine regression (vanishing testis), agenesis (true monorchia), intra-abdominal location, inguinal location with grades of dysplasia, or atrophy, or a position of the testis is outside its usual route of descent. ${ }^{5}$

An appropriate and timely management is prime importance in undescended testis because an early postnatal step in the development of the germ cells is deficient in infants with cryptorchidism. ${ }^{6}$ Moreover, cryptorchidism is associated with 2.7 times greater risk of testicular cancer. ${ }^{7}$

Among the various imaging modalities ultrasonography is the commonly performed imaging for a case of undescended testis especially in remote areas of our country. However, other imaging modality like Magnetic Resonance Imaging or MRI, is also used to identify the nonpalpable testis. However, each of these diagnostic modalities has their own limitations. The diagnosis is usually conformed by diagnostic laparoscopy if still inconclusive. Diagnostic laparoscopy is said to be the gold standard diagnostic modality in a case of undescended testis. Moreover, it is not only diagnostic but can be therapeutic as well. Thus, depending on the diagnostic laparoscopy findings, a decision for further management is followed. In the present study, we compare the ultrasonography and the diagnostic laparoscopy findings in nonpalpable testis.

\section{METHODS}

This is a cross-sectional study conducted among patients with a diagnosis of impalpable testis who presented to the paediatric surgery Outpatient Clinic in King George Hospital, Visakhapatnam, between October 2018 and March 2020, which was confirmed by physical examinations. The children were examined in a frog legged supine position. In all these patients, on an outpatient basis, USG was advised. On USG the specific features like position of the testis i.e. at the iliac bifurcation, at the deep inguinal ring, at the inguinal canal, at the superficial ring was noted. The size of the testis was also noted. After the USG findings, if the patients were fit for anaesthesia, they were planned for a diagnostic laparoscopy and depending on the laparoscopy findings, we proceeded to the appropriate surgery.

All the patients are operated under general anaesthesia in supine position with $30^{\circ}$ Trendelenburg tilt. The first port for the telescope is placed through the umbilical tube by open technique by sub-umbilical transverse incision. Two 5-mm ports are used on either side in the lower quadrants at the level of umbilicus along the mid clavicular line. Initially, diagnostic laparoscopy is performed to locate the testis, note its size, distance from the internal ring and iliac vessels, presence of hernia, if any, and the length of loop of vas deferens. If the testis is absent in the peritoneal cavity, presence of vas deferens and testicular vessels was confirmed. We also tried to observe and to know whether the vas deferens and testicular vessels are present but if they end blindly and whether vas deferens and vessels are entering the inguinal canal.

If intra-abdominal testes were detected, evaluation concerning whether they could be brought down into the scrotum without tension by bringing the testis till the contralateral deep ring done. If there was no tension in bringing the testes till the deep inguinal ring, laparoscopicassisted orchidopexy done. If there was tension, two-stage Fowler-Stephens technique planned.

If remnants of testes were present or if the vas deferens and vessels entered the inguinal canal, the procedure continued with exploration and orchidectomy of the atrophic testis done. If the testes found to be atrophic intraabdominally, a laparoscopic orchidectomy performed. Statistical analysis done by calculating accuracy, Sensitivity, specificity for selected tests.

\section{RESULTS}

A total of 20 patients included in the study. Only 1 patient presented to us before 1 year of age. But unfortunately, most of our patients (95\%) presented after 1 year of age. Most of the cases were unilateral i.e. 80\% (16). However, of these the left sided cases were more than the right. There were about $45 \%$ (9) left-sided cases and there were 35\% (7) right sided cases. There were $4(20 \%)$ bilateral cases. In about $25 \%$ of cases the testis was located at the deep inguinal ring, whereas $70 \%$ cases it was located intra-abdominally, although in 2 cases the testes were tiny like a nubbin. In 1 case, the vessels and the vas seen to enter the deep inguinal ring, hence inguinal exploration was done, however, as only a nubbin found on exploration, orchidectomy done.

\begin{tabular}{|ccc|}
\hline Age of the Patient & No. of Patients & $\mathbf{\%}(\mathbf{n = 2 0})$ \\
$<1$ yr. & 1 & $5 \%$ \\
1 to 2 years & 6 & $30 \%$ \\
2 to 4 years & 4 & $20 \%$ \\
4 to 6 years & 9 & $45 \%$ \\
Total & $\mathbf{2 0}$ & \\
\hline \multicolumn{2}{r}{ Table 1. Age Distribution } \\
\hline
\end{tabular}




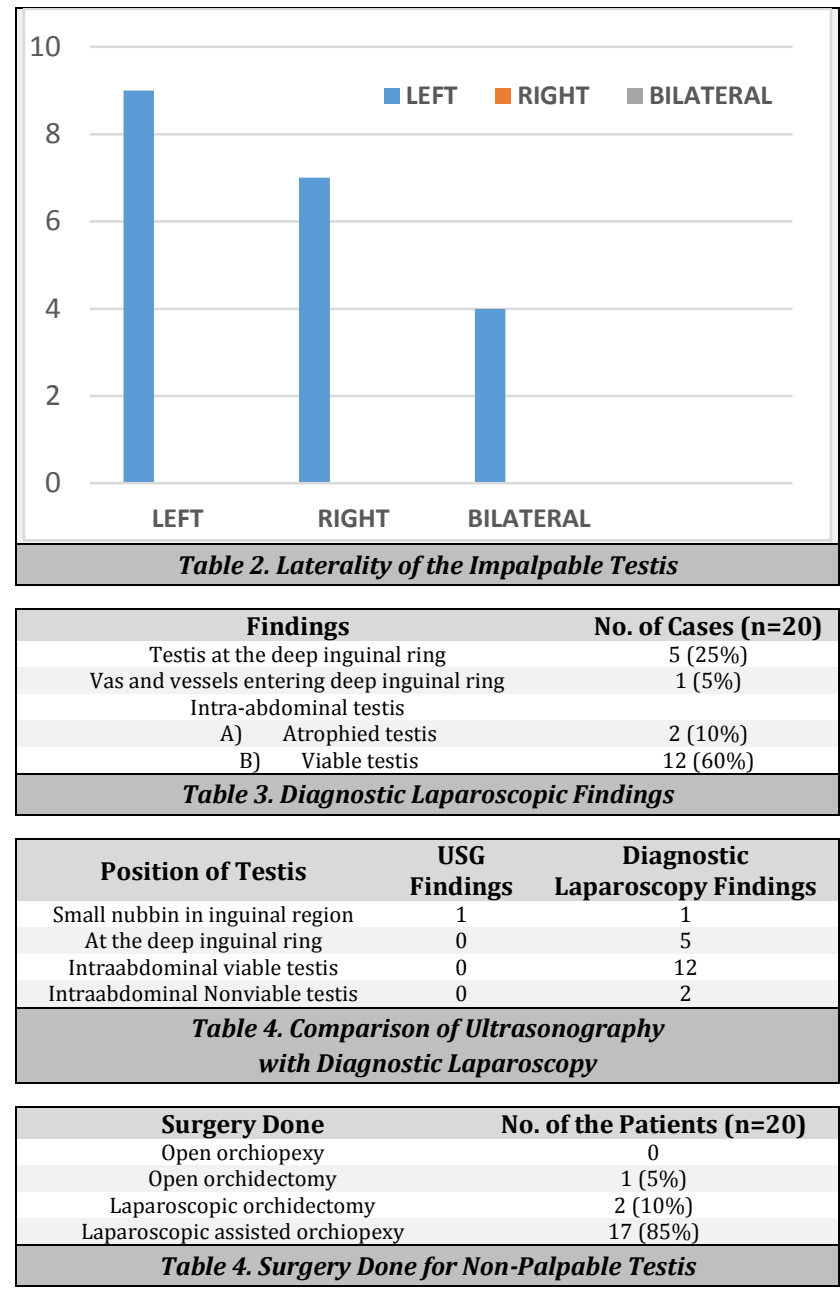

When the findings of ultrasonography and diagnostic laparoscopy was compared, it was found that for impalpable testis either at the deep ring or intrabdominal testis USG is neither accurate, sensitive nor specific whereas diagnostic laparoscopy has $100 \%$ accuracy, $100 \%$ sensitivity and $100 \%$ specific for all positions of impalpable testis. However, for inguinal testis USG has $100 \%$ accuracy, is $100 \%$ sensitive as well as $100 \%$ specific and can even pick up small nubbin specially in thin patients. Inguinal exploration was done in only 1 patient as the vessels were seen entering the deep ring. In this patient a nubbin was found on exploration and hence orchidectomy was done and thus the nubbin removed. In the rest of the patients it was managed laparoscopically. Of these in 2 patients, laparoscopic orchidectomy, and for the rest of the patient laparoscopic-assisted orchiopexy done.

\section{DISCUSSION}

Cryptorchidism or undescended testis i.e. absence of testis in the scrotum, is a common disorder encountered in a male child. Undescended testis is classified mainly depending on the clinical examination. The absence of testis in the scrotum is always a cause of concern for the parents. To add to this, if the testis could not be palpated by the examining physician or the surgeon or if on investigation, the testis could not be located, it makes them more worried about its consequences like fertility.
Some parents may feel relief with an absent or agenesis of the testis as this has no operative risk and saves money due to lack of surgical intervention. However, if misdiagnosed, the child is at risk of infertility and testicular cancer in the future. Hence a detailed and proper examination by an experienced surgeon and further detailed diagnostic evaluation should be done so that a timely intervention to avoid the risks mentioned above, done.

Depending on provider preference and age of the child, they may be examined in a frog legged supine position, sitting with legs crossed, or standing. Assistance with keeping the child still facilitates the examination of the testis. Abducting the thigh also helps to inhibit the cremasteric reflex and thus limits testicular elevation from the elicitation of this reflex. ${ }^{8}$ Clinically an undescended testis can be classified into a palpable and non-palpable testis. Approximately $80 \%$ of the undescended testes are palpable and rest $20 \%$ are nonpalpable on clinical examination. ${ }^{4}$

The palpability of the undescended testis is the most critical aspect of the evaluation of a child with cryptorchidism as palpability determines the surgical approach. There are different possible findings on physical examination when a testis is not descended to the correct position. An undescended testis may be located in the abdomen, the inguinal canal, the superficial inguinal pouch, and the upper scrotum. It is also possible that the testis may be in an ectopic position such as the perineum, contralateral scrotum, or femoral region. In our study, in about $25 \%$ of cases, the testis was located at the deep inguinal ring, whereas $70 \%$ cases it was located intraabdominally. However, in 2 cases, the testes were tiny like a nubbin. In 1 case, the vessels and the vas seen to enter the deep inguinal ring, hence inguinal exploration was done, however, as only a nubbin found on exploration, orchidectomy done.

When the testis is palpable, an inguinal or prescrotal orchiopexy is the preferred approach as the location of the testis is known to be distal to the internal ring. However, if the testis remains nonpalpable clinically or even under anesthesia, laparoscopy is the preferred diagnostic and therapeutic approach.

Progressive germ and Leydig cell loss are associated with longer lengths of time a testis remains undescended ${ }^{9}$. In order to decrease the risk of impaired fertility and testicular cancer, the recently published American Urological Association (AUA) guidelines recommend that surgery should be performed within the next year if testicular descent does not occur by 6 months (corrected for gestational age). ${ }^{10}$

Despite the recommendations for the treatment of the cryptorchid testis before 2 years of age, many of our patients presented to us at more than 2 years (65\%). The reason for this may be due to the socio-economic characteristics of the public health system in our country, the lack of parental information and demanding access to tertiary health care. Although fertility compromised in this age group, treatment is necessary not only for the risk of malignancy but also for satisfaction and improvement in the quality of the patient's life and parents' concern for their children's health. ${ }^{11}$

Imaging modalities like ultrasound is usually the first investigation done as it is said to be the extension of the clinical examination. However, it is not the case in undescended testes. It is non-invasive, comparatively less costly, and easily available even in the remote areas of our country. Hence most of the parents presented to us with preformed 
ultrasonography suggestive of the absent testis. Despite a sensitivity of $70-90 \%$ in the diagnosis of inguinal testes, ultrasonography is not useful in intra-abdominal cases.12 Ultrasonography is operator dependent. In the peripheries, the lack of experienced sonologist is a well- known factor. To add to this, even with experienced hands, the quality of the sonography machine is essential, which is another limiting factor, especially in patients from peripheries with financial constraints. High-resolution ultrasonography is more sensitive to pick up an intra-abdominal testis; however, the cost of the machine is a significant limitation, especially in a developing country like us.

At this point, it must be emphasized that the overuse of imaging by primary care providers likely stems from the erroneous belief that ultrasound is a reliable way to identify nonpalpable testis. An ancillary hypothesis is that referring providers do not realize the fact that diagnostic imaging would not change the operative approach and the surgical decisionmaking. Knowledge of the nonutility of imaging needs to be disseminated to primary care providers. Younger practitioners and those not practicing in an academic environment may be particularly important populations to target as these were provider characteristics associated with high use of ultrasound. In our study also, it was noted that most of the patients has already got the ultrasound done when they reached us.

Other diagnostic modalities like MRI introduced recently, has a sensitivity of $96 \%$ and specificity $100 \%$. The advantage of MRI is that there is no radiation risk, but the long duration and the need for anesthesia or sedation to overcome the motion artifacts, particularly in the pediatric age group, limits its use. ${ }^{13}$ Moreover, other limitations, including more limited availability and high cost, further limits its use as a diagnostic modality in undescended testis.

The use of laparoscopy in nonpalpable testis dates back to 1976 when Cortesi et al. ${ }^{14}$ 1st reported its use in impalpable testis. Laparoscopy is considered the gold standard for diagnosing nonpalpable testis. Moreover, laparoscopy not only can confirm the presence and locate the position of the testis, but it also evaluates whether the testis can be brought down to the scrotum or not without tension.

In our study, $20 \%$ of the cases were bilateral, $45 \%$ leftsided, and the rest were right-sided. About $25 \%$ cases the testis was located at the deep inguinal ring which could have been picked up by ultrasonography, whereas $70 \%$ cases were intra-abdominal, In our study for impalpable testis either at the deep ring or intrabdominal testis USG is neither accurate, sensitive nor specific whereas diagnostic laparoscopy has $100 \%$ accuracy, $100 \%$ sensitivity and $100 \%$ specific for all positions of the impalpable testis. However, for inguinal testis, USG has $100 \%$ accuracy, is $100 \%$ sensitive as well as $100 \%$ specific and can even pick up small nubbin specially in thin patients.

In most of the cases, $17 / 20$ patients were managed with laparoscopic-assisted orchiopexy. Unfortunately, in 2/20 cases, the testes were tiny like a nubbin; hence laparoscopic orchidectomy was done. In 1/20 patients, the vessels and the vas enter the deep inguinal ring; hence inguinal exploration was done, however, as only a nubbin found on exploration orchidectomy done.

Our results also support the findings of Elder, ${ }^{15}$ who concluded that: "ultrasonography is not necessary in boys with nonpalpable testis as it rarely if ever localizes a true nonpalpable testis; moreover, it does not change the surgical approach in such cases." In a 2011 article, Tasian and Copp ${ }^{16}$ concluded that: "ultrasound does not reliably localize an impalpable testis and also does not rule out an intraabdominal testis."

Preoperative imaging does not change the surgical management of non-palpable testes because a reliable imaging modality is not yet available that can be used in lieu of the gold standard of laparoscopy to correctly identify the presence and location of a non-palpable undescended testis. Additionally, by ordering preoperative imaging in these cases, one may be delaying evaluation and treatment by a surgical specialist, adding to the costs of our healthcare system, and subjecting a child and family to unnecessary testing.

Laparoscopic orchiopexy presents excellent results in terms of diagnosis and therapy of the impalpable testis, which is why this technique routinely incorporated in our department. It is noteworthy that our preference is the primary orchiopexy without transection of the gonadal vessels. However, in cases of very high testicles or those with shortened vessels, we now recommend the two-staged laparoscopic technique of Fowler-Stephens.

\section{CONCLUSIONS}

Preoperative diagnostic modalities like ultrasound has no role in the evaluation of nonpalpable testis. Laparoscopy is the preferred diagnostic modality in an undescended testis. Laparoscopy presents excellent results in terms of diagnosis and therapy of the impalpable testis. Diagnostic laparoscopy is more sensitive in localizing a nonpalpable testis; it is more time- and cost-effective. Moreover, laparoscopy is diagnostic as well as therapeutic in nonpalpable testes. Hence it can be concluded that laparoscopy is superior to ultrasound, which is less sensitive and operator dependent, especially in the management of impalpable testes. Moreover, primary health care providers should be well informed that in case of nonpalpable testis rather than advising for an ultrasound to locate the testis, they better refer them to higher centres where a proper and timely intervention can be done.

Financial or Other Competing Interests: None.

\section{REFERENCES}

[1] Ashley RA, Barthold JS, Kolon TF. Cryptorchidism: pathogenesis, diagnosis, treatment and prognosis. Urol Clin North Am 2010;37 (2):183-93.

[2] Barteczko KJ, Jacob MI. The testicular descent in human. Origin, development and fate of the gubernaculum Hunteri, processus vaginalis peritonei, and gonadal ligaments. Adv Anat Embryol Cell Biol 2000;156: III-X, 198.

[3] Khatwa UA, Menon PS. Management of undescended testis. Indian J Pediatr 2000;67 (6):449-54.

[4] Guvenc BH, Sozubir S, Ekingen G, et al. Advantages of video-assisted approach in detecting epididymal 
anomalies and treatment of nonpalpable testis. Urol Int 2005;74 (2):127-34.

[5] Mouriquand PDE. Undescended testes in children the paediatric urologist's point of view. Eur J Endocrinol 2008;159 (Suppl 1):83-6.

[6] Mengel W, Hienz HA, Sippel WG, et al. Studies on cryptorchidism: a comparison of histological findings in the germinative epithelium before and after the second year of life. J Pediatr Surg 1974;9 (4):445-50.

[7] Pettersson A, Richiardi L, Nordenskjold A, et al. Age at surgery for undescended testis and risk of testicular cancer. N Engl J Med 2007;356 (18):1835-41.

[8] Barthold JS. Abnormalities of the testis and scrotum and their surgical management. In: Wein AJ, Kavoussi LR, Novick AC, et al, eds. Campbell-Walsh urology. $10^{\text {th }}$ edn. Philadelphia, PA: Saunders Elsevier 2011:3557-95.

[9] Tasian GE, Hittelman AB, Kim GE, et al. Age at orchiopexy and testis palpability predict germ and Leydig cell loss: clinical predictors of adverse histological features of cryptorchidism. J Urol 2009;182 (2):704-9.
[10] Kolon TF, Herndon CDA, Baker LA, et al. Evaluation and treatment of cryptorchidism: AUA guideline. J Urol 2014;192 (2):337-45.

[11] Kucheria R, Sahai A, Sami TA, et al. Laparoscopic management of cryptorchidism in adults. Eur Urol 2005;48 (3):453-7.

[12] Kolon TF, Patel RP, Huff DS. Cryptorchidism: diagnosis, treatment, and long-term prognosis. Urol Clin North Am 2004;31(3):469-80.

[13] Eggener SE, Lotan Y, Cheng EY. Magnetic resonance angiography for the nonpalpable testis: a cost and cancer risk analysis. J Urol 2005;173 (5):1745-9.

[14] Cortesi N, Ferrari P, Zambarda E, et al. Diagnosis of bilateral abdominal cryptorchidism by laparoscopy. Endoscopy 1976;8 (1):33-4.

[15] Elder JS. Ultrasonography is unnecessary in evaluating boys with a nonpalpable testis. Pediatrics 2002;110 (4):748-51.

[16] Tasian GE, Copp HL. Diagnosis performance of ultrasound in nonpalpable cryptorchidism: a systematic review and meta-analysis. Pediatrics 2011;127 (1):119-28. 